\title{
STUDY ABOUT NOISE LEVELS IN UNIVERSITY STUDENTS' LEISURE AREAS: A BARRIER AGAINST NOISE
}

\author{
M.C. Ruiz-Grao ${ }^{1,2}$, A. Hernández-Martínez ${ }^{1,2,3}$, F. García-Alcaraz ${ }^{1,2}$, M. García-Moreno ${ }^{4}$, M.LL. \\ Amo-Saus $^{4}$, L. Martínez-Esparcia ${ }^{5}$, A. García-López ${ }^{6}$, M. Molina-Alarcón ${ }^{1,2}$ \\ ${ }^{1}$ Instituto de Investigación en Discapacidades Neurológicas (IDINE). Universidad de Castilla-La \\ Mancha (SPAIN) \\ ${ }^{2}$ Facultad de Enfermería de Albacete. Universidad de Castilla-La Mancha (SPAIN) \\ 3 Gerencia de Atención Integrada de Alcázar de San Juan. SESCAM (SPAIN) \\ ${ }^{4}$ E.S. Ingenieros Industriales. UCLM (SPAIN) \\ ${ }^{5}$ Conservatorio de Música. AMUCLM (UCLM) (SPAIN) \\ ${ }^{6}$ Enfermero SESCAM (SPAIN)
}

\begin{abstract}
Introduction/Background: The World Health Organization (WHO) considers that noise-related problems can mean health problems. Around $22 \%$ of the population in Europe feels affected by the effect of noise. Noise pollution is understood as excess sound that alters the normal conditions of a given area in particular, and of living beings in general. Excess sound is known as noise, which causes noise pollution.
\end{abstract}

Nowadays, the way youths enjoy themselves centres on noise, particularly music, with levels that exceed $100 \mathrm{dBA}$ in leisure areas. Thus noise has become a serious pollution factor and its effects accumulate. Youths more frequently attend these areas who are unaware of the damaging effects of this exposure.

The WHO has classified noise effects on the organism into different sections according to their specific effects: Hearing deficiency; Interference in oral communication; Sleep disorders; Physicophysiological effects on mental health and performance; effects on conduct; interference with activities. In relation with the learning process, it has been observed that apart from noise producing impaired hearing among students, it also alters sleep, causes stress and leads to the development of vocal nodules. A series of cognitive effects directly associated with the learning process has also been related given its effect on memory, attention, motivation, and a series of underlying mechanisms and processes.

Evaluating the noise level to which university students are exposed in their leisure time has been considered interesting given its implication as a possible barrier against the learning process. Awareness can be raised from the classroom by means of those subjects where these problems to be studied are dealt with; e.g., the Biochemistry subject in Nursing Degree studies.

Objective: To know noise levels in the leisure areas to which university students from Albacete (Spain) frequently attend.

Method: An observational, descriptive and cross-sectional study that randomly selected 12 leisure areas in the city of Albacete. The dependent variable was the equivalent continuous noise level that students were submitted to in their leisure time, while the independent variables were the places where distributed measurements were taken in turns, defined as evening and nighttime.

The instrument that measured the noise levels was a Bruel \& Kjaer sound level meter type 2.226, collected in Leq dBA.

Results: The mean noise levels measured in the defined turns was 78.7 dBA (SD: 4.14 dBA), with higher levels measured in the nighttime turn with a mean of $83.2 \mathrm{dBA}$ (SD: $9.48 \mathrm{dBA}$ ). A statistically significant association between the noise levels measured at weekends and on weekdays $(p<0.05)$ was observed.

Conclusions: The noise levels taken in the leisure areas to which university students frequently attend exceeded the limits considered by the WHO as recommendable (65.0 dBA). However, noise levels did not exceed the limits set by current legislation for leisure premises in the city of Albacete, which lie between 75.0 and $90.0 \mathrm{dBA}$. It would be interesting to make our students aware in class about noise problems, mainly the negative effects that noise can have on their learning process.

Keywords: Noise, Noise levels, University students, Leisure areas, Barrier, Learning. 


\section{INTRODUCTION}

The World Health Organization (WHO) considers that noise-related problems can be a major health problem [1] as hearing is fundamental for people's well-being and security. About $22 \%$ of the European population states that they feel affected by noise effects [2]. European Directive 2002/49/EC on Assessment and Management of Environmental Noise, adopted in Spanish legislation by Law $37 / 2003$, of 17 November on Noise, defines environmental noise as non-desired or harmful outdoor noise generated by human activities, including the noise caused by road, rail and air traffic, and by industrial activity placements. Noise is a specific kind of undesired sound constituted by two main components, a physical and a subjective one, which is felt as being a nuisance, especially if we bear in mind that the human ear is able to support sound pressure levels from 0 to 120 decibels (dB) [3]. Noise pollution is understood as excess noise that alters normal living conditions in a given area in particular, and bothers living beings in general. Excess sound is known as noise, which causes noise pollution.

Nowadays, the main forms of leisure and entertainment enjoyed by young people involve noisy conditions, mainly high levels of music. Not only listening to music individually with earplugs, but also visiting leisure areas (nightlife, sporting events and concerts, etc.), involve noise levels that often exceed 100 adjusted decibels (dBA). So noise has become a serious polluting factor whose effects accumulate [4] [5]. Youths frequent these areas more and are unaware of the harmful effects that this exposure has.

The WHO has classified noise effects on the organism into different sections according to their specific effects: Hearing deficiency; Interference with oral communication; Sleep disorders; Physicophysiological effects on mental health and occupational/educational performance; effects on performance; nuisance; hormone responses (metabolic and/or immune effects); interference with activities [6]. In auditory terms, which could be of more concern for the subjects who suffer it, it can be stated that hearing deficiency has increased in adolescents in recent years both acutely and chronically, and even hypoacusis is present. According to one study, youths could lose their hearing 30 years before previous generations did [7][8]. Sleep disorders are also frequently related with noise. Noise levels should not exceed $30.0 \mathrm{dBA}$ to be able to sleep properly. The harmful effects of noise quite often affect not only the people who frequent noise leisure areas, but also the people who live near these places. This has led to various initiatives being taken to fight environmental noise; e.g., European, national, regional and local decrees, laws or directives. [3]. In the learning process, it has been observed that apart from the possibility of students suffering hearing deficiency, noise also alters sleep, causes stress, and facilitates the development of vocal cord nodules. Noise has also been related with a series of cognitive effects that have been directly associated with the learning process given its repercussion on memory, attention, motivation, and a series of underlying mechanisms and processes [9]. Two types of failing memory have been related with noise: one related to subjective content and another to remembering accidental details. Deficits in performance can lead to mistakes and accidents. Reading comprehension, and cognitive and language development, have been found to diminish in noisy homes. Noise can reduce attention when performing a task, and can affect social skills, capturing relevant social clues, etc. [1].

The main objective of the present study, given the interest it has, is to know the noise levels in the leisure areas frequented by young university students in the city of Albacete (Spain). As some studies have evidenced, a certain degree of implication could exist that may act as a possible barrier against the learning process. We could raise awareness in classrooms through those subjects that deal with the problem under study, such as the biochemistry subject in Nursing Degree studies because our students are often unaware of the harmful effects that their forms of leisure and the accumulative effect of noise may have throughout their lives.

\section{OBJECTIVE}

Overall objective: identify the noise levels in the leisure areas frequented by our Albacete university students.

Specific objectives:

- Describe the socio-demographic characteristics of the leisure areas frequented by our university students.

- Know the noise levels in different leisure areas. 
- Determine the possible relation between noise levels and the studied covariables.

\section{METHOD}

\subsubsection{Study type}

The present research was conducted as an observational, descriptive and cross-sectional study.

\subsubsection{Place/area to conduct the study and study period}

Twelve leisure areas were randomly selected in the city to which university students in Albacete often frequent.

Measurements were taken during 1 week, from 10 to 17 December 2016.

\subsubsection{Study population and sampling method}

The study population was the leisure areas by the university students on a regular basis (measurement unit). The sampling method was non-probabilistic sampling. Twelve leisure areas were selected (bars-cafés, cinemas, fast-food restaurants, discos and sports centres in the city of Albacete).

\subsubsection{Inclusion criterion}

The following inclusion criterion was considered: the leisure areas/establishments frequented by university students that freely and willingly accepted to participate in the present study where the corresponding measurements were taken.

\subsubsection{Study variables}

Dependent variable. The Dependent variable was the equivalent continuous noise level (Leq in dBA).

Independent variables. Leisure areas where measurements were taken on weekdays (Monday, Tuesday and Wednesday) and at/towards the weekend (Thursday, Friday and Saturday); day of the week and turn: daytime (07:00-19:00h), evening (19:00-23:00h) and nighttime (23:00-7:00h). The times of the variable turns were defined according to RD 1720/2007.

\subsubsection{Sources of information}

The used measuring instrument was a Bruel \& Kjaer type 2.226 sound level meter, which measures the equivalent continuous noise level (Leq in dBA) (Fig. 1).

Measurements were recorded in the centre of each leisure area. The moment of peak activity in the selected places was taken into account depending on the turn: daytime, evening and nighttime. Five approximate measurements were taken in each area.

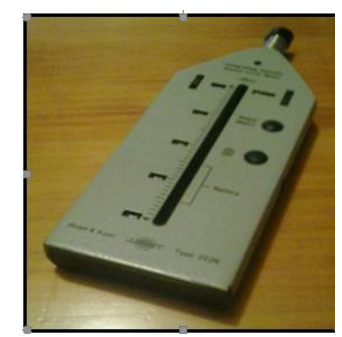

Figure 1. The Bruel \& Kjaer type 2.226 sound level meter model used

\subsubsection{Statistical analysis}

A descriptive statistical analysis was done using proportions and measures of central tendency/dispersion. A $95 \% \mathrm{Cl}$ was taken. The verification of the associations among the main variables were done using tests to compare means (Student's $t$ ) and proportions (Chi-squared), depending on the nature of the variables. The level of significance was $p<0.05$. Data were analysed using the SPSS v. 23.0. software. 


\subsubsection{Ethical aspects}

The present research takes into account the General Provisions set out in the General Law on Health in Research Matters [14]. The criterion adopted to respect the dignity of the study subjects, and to protect their rights and well-being, prevails in this research. Therefore, all the measurements taken in the different selected leisure areas were taken after obtaining informed consent from the owners of these establishments. Therefore, the privacy of these establishments was respected at all times by complying to anonymity and confidentiality. The Personal Data Protection Act was also taken into account [10].

\section{RESULTS}

\subsubsection{Descriptive analysis}

The sample was made up of five (41.7\%) café-bares, three (25.0\%) fast-food restaurants, two (16.7\%) discos, one (8.3\%) cinema and one (8.3\%) sports centre. These 12 leisure areas were selected in which the corresponding equivalent noise level measurements were taken during the study period. The highest noise level was recorded in discos with 90.8 Leq dBA (SD: 0.6), followed by the sports centre with 77.6 Leq dBA (SD: 1.4) and cafés-bars with 77.5 Leq dBA (SD: 2.9). Lower values were measured in all the other leisure areas (Table 1)

Table 1. Leisure areas and Leq dBA measurements

\begin{tabular}{|l|c|c|}
\hline \multicolumn{1}{|c|}{ Area } & No. (\%) & Noise Level $^{\star}$ \\
\hline Café-Bar & $5(41.7)$ & 77.5 (SD: 2.9$)$ \\
Restaurants & $3(27.3)$ & 75.6 (SD: 6.4$)$ \\
Disco & $2(18.2)$ & $90.8($ SD:0.6) \\
Cinema & $1(9.1)$ & $71.3($ SD:8.0) \\
Sports centre & $1(9.1)$ & $77.6($ SD: 1.4$)$ \\
\hline
\end{tabular}

$\left(^{\star}\right)$ Noise level measured in Leq dBA

From the maximum and minimum noise levels recorded during the different turns (daytime, evening and nighttime) in the 12 leisure areas during 1 week, the maximum daytime noise level was $79.5 \mathrm{dBA}$ (SD:0.7) on Monday, Friday and Saturday. The minimum value was recorded on Tuesday with 64.5 dBA (SD:5.7) (Table 2).

Table 2. Noise level and measuring turn

\begin{tabular}{|c|c|c|c|}
\hline Day of the week & \multicolumn{3}{|c|}{ Noise level } \\
\hline & Mean (SD) & Range & $95 \% \mathrm{Cl}$ \\
\hline Maximum daytime noise level & $79.5(0.7)$ & $80.0-79.0$ & {$[80.5-78.5]$} \\
\hline Monday & $78.0(3.0)$ & $81.0-73.5$ & {$[80.6-75.4]$} \\
\hline
\end{tabular}




\begin{tabular}{|c|c|c|c|}
\hline Friday & $79.5(0.7)$ & $80.0-79.0$ & {$[80.5-78.5]$} \\
\hline Saturday & $79.5(0.7)$ & $80.0-79.0$ & {$[80.5-78.5]$} \\
\hline \multicolumn{3}{|l|}{ Minimum daytime noise level } & {$[78.0-78.0]$} \\
\hline Monday & $78.8(0)$ & $78.0-78.0$ & {$[69.5-59.5]$} \\
\hline Tuesday & $64.5(5.7)$ & $71.0-57.0$ & {$[78.5-76.5]$} \\
\hline Friday & $77.5(0.7)$ & $78.0-77.0$ & {$[79.5-77.5]$} \\
\hline Saturday & $78.5(0.7)$ & $79.0-78.0$ & \\
\hline
\end{tabular}

$\left(^{*}\right)$ Noise level measured in Leq dBA

In the evening, the maximum noise level was $81.5 \mathrm{dBA}$ (SD: 0.7) on Saturday, and the minimum noise level was $68.0 \mathrm{dBA}$ (SD: 5.7) on Thursday (Table 3). At nighttime, the maximum noise level was 93.0 dBA (SD:1.4). Tuesday nighttime was the nighttime turn with the lowest noise level of $74.5 \mathrm{dBA}$ (SD:0.6) (Table 4).

Table 3. Noise level and measuring turn

\begin{tabular}{|c|c|c|c|}
\hline \multirow[t]{2}{*}{ Day of the week } & \multicolumn{3}{|c|}{ Noise level } \\
\hline & Mean $(S D)$ & Range & $95 \% \mathrm{Cl}$ \\
\hline \multicolumn{4}{|c|}{ Maximum evening noise level } \\
\hline Monday & $79.0(0)$ & $79.0-79.0$ & {$[79.0-79.0]$} \\
\hline Thursday & $74.3(1.1)$ & $75.0-73.5$ & {$[75.8-72.8]$} \\
\hline Saturday & $81.5(0.7)$ & $82.0-80.0$ & {$[82.5-80.5]$} \\
\hline \multicolumn{4}{|c|}{ Minimum evening noise level } \\
\hline Monday & $76.5(0.7)$ & $77.0-76.0$ & {$[77.5-75.5]$} \\
\hline Thursday & $68.0(5.7)$ & $72.0-64.0$ & {$[75.8-60.2]$} \\
\hline Saturday & $80.5(0.7)$ & $81.0-80.0$ & {$[81.5-79.5]$} \\
\hline
\end{tabular}

Table 4. Noise level and measuring turn 


\begin{tabular}{|c|c|c|c|}
\hline & Mean (SD) & Range & $95 \% \mathrm{Cl}$ \\
\hline \multicolumn{4}{|c|}{ Maximum nighttime noise level } \\
\hline Tuesday & $77.0(1.8)$ & $79.0-75.0$ & [78.8-75.2] \\
\hline Wednesday & $82.8(0.4)$ & $83.0-82.5$ & [83.3-82.3] \\
\hline Saturday & $93.0(1.4)$ & $94.0-92.0$ & {$[95.0-91.0]$} \\
\hline \multicolumn{4}{|c|}{ Minimum nighttime noise level } \\
\hline Tuesday & $74.5(0.6)$ & $75.0-74.0$ & [75.1-73.9] \\
\hline Wednesday & $80.5(0)$ & $80.5-80.5$ & {$[80.5-80.5]$} \\
\hline Saturday & 87.5 (3.5) & $90.0-85.0$ & [92.4-82.6] \\
\hline
\end{tabular}

Figure 2 shows the mean equivalent noise level (Leq dBA) recorded in the 12 leisure areas for each day of the week. Thursday obtained the lowest level (70.9, SD:3.8), measured in two leisure areas. Saturday obtained the highest level (85.4, SD:6.3), measured in four leisure areas.

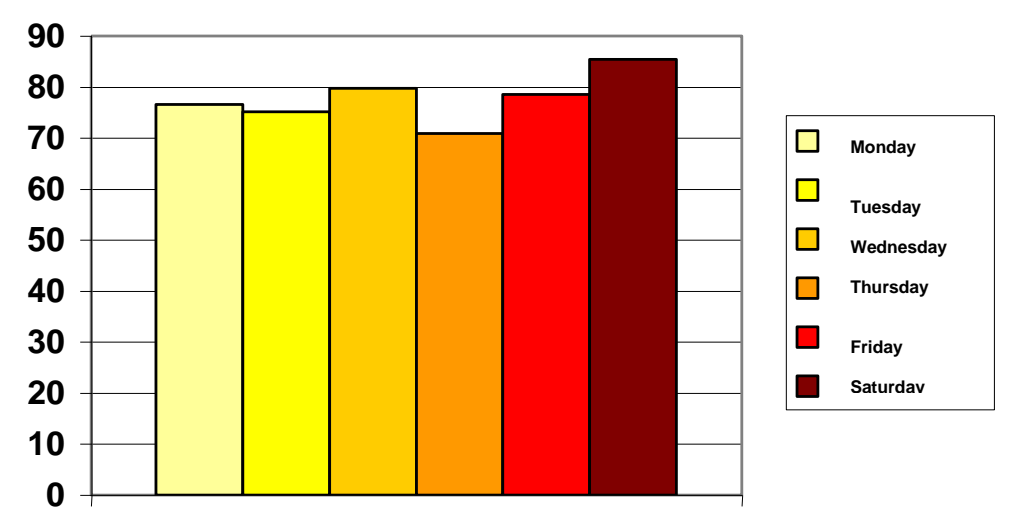

\section{Leq dBA measures}

Figure 2. Mean noise level (Leq dBA) according to day of the week

The mean noise levels according to turns were higher for nighttimes: 83.2 (SD:9.5) (Table 5; Fig.3).

Table 5. Leq measures for the Turn variable 


\begin{tabular}{|l||c|c|c|c|}
\hline \multicolumn{1}{|c|}{ TURN } & $\begin{array}{c}\text { Percentage } \\
\text { (\%) and } \\
\text { (No.) }\end{array}$ & Leq dBA & Max. Leq dBA & Min. Leq dBA \\
\hline Daytime & $33.3(4)$ & $78.0(\mathrm{DE}: 1.7)$ & 80.0 & 74.0 \\
\hline Evening & $33.4(4)$ & $75.0(\mathrm{DE}: 5.41)$ & 82.0 & 64.0 \\
\hline Nighttime & $33.3(4)$ & $83.2(\mathrm{DE}: 9.5)$ & 94.0 & 57.0 \\
\hline
\end{tabular}

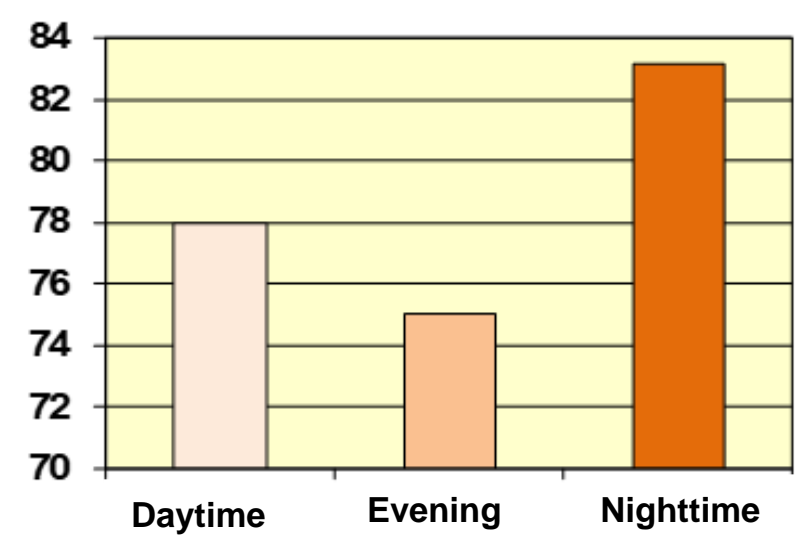

Figure 3. Mean sound level (Leq dBA) according to Turn

The percentage of measurements taken on weekdays and on weekend days was higher for the latter (58.3\%). The highest mean noise level was recorded at the weekend (80.3, SD:8.3) (Table 6).

Table 6. Measurements taken and mean noise levels according to weekdays and weekend days

\begin{tabular}{|c|c|c|c|}
\hline & Absolute No. & Percentage (\%) & Measured Leq dBA \\
\hline Weekday & 5 & 41.7 & 76.6 (SD: 3.35) \\
\hline Weekend & 7 & 58.3 & 80.3 (SD: 8.3) \\
\hline TOTAL & 12 & 100 & \\
\hline
\end{tabular}

\subsubsection{Bivariate analysis}

After performing the analysis with a Chi-squared test $\left(x^{2}\right)$ among all the independent variables, we concluded that a statistically significant relation existed between the variable days of the week and the variable weekend days and weekdays $(p<0.05)$ (Table 7$)$. 
Table 7. Contingency table - Chi-squared $\left(x^{2}\right)$ (noise levels on week days and on weekend days).

\begin{tabular}{|l|r|r|r|}
\hline & \multicolumn{1}{|c|}{ Chi - squared tests } \\
\hline & \multicolumn{1}{|c|}{ Value } & Gl & $\begin{array}{l}\text { Asymptotic } \\
\text { significance } \\
\text { (bilaterall) }\end{array}$ \\
\hline Pearson's Chi-square & 12,000 & 5 &, 035 \\
Likelihood ratio & 16,301 & 5 &, 006 \\
Linear by linear association & 8,927 & 1 &, 003 \\
No. of valid cases & 12 & & \\
\hline
\end{tabular}

However, after performing the statistical Student's t-test to evaluate the association among the maximum and minimum mean Leq measurements of the three turns (daytime, evening and nighttime), no statistically significant differences were observed between the different measured areas and weekdays/weekend days ( $p>0.05)$.

\section{DISCUSSION}

The present research was designed as a descriptive, observational and cross-sectional study carried out in twelve different leisure areas frequented by the university students from our Albacete campus. Its main objective was to centre on identifying the noise levels in these leisure areas, know their sociodemographic characteristics, the existing noise levels in them, and determine the possible relation between noise levels and a series of studied covariables.

Our research results evidenced that young university students were exposed to higher noise levels than the desirable healthy ones that the WHO considers suitable. These levels were particularly high for nightlife, and especially and significantly so on weekend days.

The municipal legislation in the city where our study was conducted (Albacete) sets a maximum noise level of $90.0 \mathrm{dBA}^{12}$. One of the sections of the city's non-normative Civic Regulations states maximum noise levels of $75.0 \mathrm{dBA}^{13}$. Legislation on noise matters differs from one Spanish Autonomous Community (SAC) to another; for example, in the Basque Country the maximum permitted noise limit is $75.0 \mathrm{dBA}$ for cinemas and $90.0 \mathrm{dBA}$ for discos ${ }^{14}$. In some SAC, maximum noise levels are set according to the number of people that a place holds (its capacity) as this element is considered a main noise source, which is the case in Madrid. Although our study did not take into account the capacity of the 12 selected leisure areas, the noise levels fell within the maximum limits ${ }^{15}$. However, if we consider the maximum levels allowed in other countries. Spain would be well over other EU countries like Germany, Denmark, France or Italy with maximum noise limits of $70.0 \mathrm{dBA}$, or the Netherlands with $50.0 \mathrm{dBA}^{16}$. In our case, noise levels would exceed these levels for turn, day of the week and type of leisure area.

The data obtained herein remain at the global level and within the limits set by legislation. If we consider other studies conducted in Spain on noise levels in leisure areas, which have reported levels ranging from 83.0 and $109.0 \mathrm{dBA}^{17}$, we see that they exceed the measures obtained in the present study. The difference might lie in the fact that the measurements taken in other works conducted in Spain were taken only at nighttime on Fridays and Saturdays over a 2-month period and from 01:00h to $06: 00 \mathrm{~h}$. In our work, measurements were taken over a 1-week period and we considered no measuring times, but turns.

Our results fall in line with other conducted studies, like the one done in the Spanish city of Valencia, where the noise level recorded for cinemas ranged from 57.0 to $81.0 \mathrm{dBA}$, although our results for discos and sports centres were slightly higher. This could be due to the difference in the number of areas where measurements were taken and the measurement times in both studies (Albacete and Valencia) ${ }^{18}$.

According to the WHO and the OECD (Organisation for Economic Cooperation and Development), noise between 55.0 and $60.0 \mathrm{dBA}$ starts to bother humans, and their disturbance increases with noise levels between 60.0 and $65.0 \mathrm{dBA}$, while altered performance can occur at levels above $65.0 \mathrm{dBA}$. 
Deafness, as a result of constant exposure to noise, affects those youths who frequent leisure areas with noise levels of $80.0 \mathrm{dBA}$. However, excess noise levels not only cause hearing problems, but also circulation of the blood, hypertension and irregular heartbeat problems at levels over $85.0 \mathrm{dBA}^{11}$. From our study we see that our youths are exposed to the possibility of suffering noise-related health and performance problems. To a certain extent, this could act as a barrier in their learning process because noise levels of $94.0 \mathrm{dBA}$ were recorded in some cases.

However, we must also bear in mind that noise may be found elsewhere, and not just in leisure areas, as a noise pollution study conducted in schools found. It has observed that as schoolchildren need to concentrate to satisfactorily learn, they are thus more susceptible to the noise risk factor, which also affects the teachers who work at schools. The main effects caused by noise that could affect schoolchildren's health were those of the hearing kind, such as the hearing threshold shifting temporarily or permanently, and those of a non-hearing kind, like dilated pupils, blinking quickly and agitated breathing, plus other psychological effects ${ }^{19}$.

The limitations of the present study include the fact that measurements were taken only over a 1-week period as this was the time during which the sound level meter was available. Moreover, there is the difficulty of extrapolating our results to other populations as sampling size was below 30 . One of its strong points is that we are unaware of similar studies performed in our city and on this population type. So the present study could be considered a first pilot approach to take more extensive measurements and with a larger sampling size in the future.

Finally, it can be stated that most of the sound levels obtained in the leisure areas of our city are framed within the legislation on this matter currently in force, except for a couple of weekend nighttime measurements. However, taking into account the negative effects of noise and the fact that they may act as a possible barrier against the learning process with a certain degree of implication [1][9], it would be interesting to raise awareness among our students in class with the curricular activities in those subjects that deal with the problems under study. More often than not, students are unaware of the harmful effect of their leisure forms, of the accumulative effect of noise throughout their lives, and of how they can protect themselves from noise and be able to enjoy proper hearing health.

\section{CONCLUSION}

The noise levels recorded in the leisure areas frequented by university students exceeded the recommended limits set by the WHO $(65.0 \mathrm{dBA})$, but did not exceed the limits set by the legislation in force for leisure areas in Albacete (Spain), which lie between 75.0 and $90.0 \mathrm{dBA}$. The levels recorded in places like cinemas, bars, fast-food restaurants and sports centres were lower than those legally allowed, but the same cannot be stated for discos and pubs at nighttime. Noise levels were higher in the evening and at nighttime on weekend days than on week days. Saturday obtained the highest noise level and Thursday the lowest.

It would be interesting to raise our students' awareness about noise problems in class with the curricular activities included in Degree studies, and precisely about the negative effect that noise has for our hearing health and on the learning process.

\section{ACKNOWLEDGEMENTS}

The present study was conducted thanks to collaboration from the Institute for Neurological Disability Research (IDINE), which belongs to the UCLM. We also wish to thank the leisure establishments in the city of Albacete that decided to unselfishly participate in our study. We thank all those people who collaborated in our study.

\section{REFERENCES}

[1] Goines L, Hagler L. Noise pollution: a modern plague. South Med J. 2007 Mar;100(3):287-94.

[2] WHO. Experts consultation on methods of quantifying burden of disease related to environmental noise. 2007. 
[3] Junta de Andalucía; Unión Europea; Observatorio de Salud y Medio Ambiente de Andalucía. Ruido y Salud. Andalucía; 2011.

[4] Berglund B, Lindvall T, Schwela HD, editors. Organización Mundial de la Salud. Guías para el ruido urbano. Ginebra: OMS; 2006.

[5] Martín Portugués C, Ortiz C. Creencias ambientales y coste social del ruido de ocio. Revista de Acústica. 2006;36(3,4):11-19.

[6] World Health Organization. Noise and Health. 2007; Available from:

http://www.euro.who.int/Noise.

[7] Shargorodsky J, G. Curhan S, Curhan CG, Eavey R. Change in Prevalence of hearing Loss in US Adolescents. American Medical Association. 2010;304(7):772-778.

[8] René Serra M, Biassoni EC, Pavlik M, Pérez Villalobo J, Hinalaf M, Abraham M, et.al. Audición en los adolescentes: un programa multidisciplinario para su conservación y promoción. Revista de Acústica. 2009;40(3,4):27-36.

[9] Bistrup ML , editor. National Institute of Public Health Denmark. Health effects of noise on children and perception of the risk of noise. Denmark: 2001.

[10] Real Decreto 1720/2007, de 21 de diciembre, por el que se aprueba el Reglamento de desarrollo de la Ley Orgánica 15/1999, de 13 de diciembre, de protección de datos de carácter personal, Boletín Oficial del Estado, №17, (19-01-2008).

[11] Biassoni EC, Serra MR, Villalobo JP, Joekes S, Yacci MR. Hábitos Recreativos en la Adolescencia y Salud Auditiva. Interam J Psychol. 2008;42(2):257-271.

[12] Ordenanza Municipal de Medio Ambiente. Boletín Oficial de la Provincia, № 127 (29 de Oct 1993).

[13] Ordenanza reguladora de los espacios públicos de Albacete para fomentar y garantizar la convivencia ciudadana y el civismo. Boletín Oficial de la Provincia, №63 (5 de Junio de 2013).

[14] Diputación Foral de Bizkaia; Departamento de Medio Ambiente. Guía técnica para el control de las actividades clasificadas respecto a la generación de ruido y vibraciones. Bizkaia: Labein Tecnalia; 2010.

[15] Ordenanza de Protección contra la Contaminación Acústica y Térmica. Boletín Oficial de la Comunidad de Madrid, no 105 (6 de Jun 2011).

[16] García de la Fuente M. Nuevos límites para España, el segundo país más ruidoso del mundo. Público [Internet].2007 Oct [citado 22 de Oct 2007]: [aprox 1p.]. Disponible en: http://www.publico.es/8272/nuevos-limites-para-el-segundo-pais-mas-ruidoso-del-mundo

[17] Discotecas y salas de fiestas: analizados 50 locales. Sobra volumen en la música y falta seguridad. Consumer. 1999 Feb [citdado 1 de Feb 1999]. [Aprox 1p.]. Disponible en: http://revista.consumer.es/web/es/19990201/actualidad/tema_de_portada/31620.php

[18] García A. La exposición cotidiana al ruido ambiental. Sociedad Española de acústica. 2004;35(3,4):36-41.

[19] González-Sánchez Y, Fernández-Díaz Y. Noise pollution in schools: its effect on the health of students and teachers. Revista Cubana de Higiene y Epidemiología. 2014;52 (3):402-410 